\title{
Smoking and obesity among long-haul truck drivers in France
}

\author{
Loic Josseran', Killian McNeill², Thierry Fardini', Rebecca Sauvagnac', Frederic Barbot' ${ }^{1}$, Maria-Antonia Quera Salva', \\ Myles Bowser ${ }^{3}$, Gary King ${ }^{2}$
}

\begin{abstract}
INTRODUCTION This study examines the health status of long-haul truck drivers (LHTDs) and more specifically smoking and obesity, in France.

METHODS A total of 373 French and other LHTDs were randomly interviewed at six highway rest stops. Variables recorded were self-reported sociodemographic characteristics (age, gender, marital status, and nationality), behavioral variables (consumption of sodas, daily exercise, smoking status), weight and height. Body mass index (BMI) was also calculated. Statistical analysis was conducted using chi-squared analysis and multiple logistic ordinal regression models (MLR) were developed.

RESULTS The mean age was 43.4 and the largest proportion (41.2\%) of respondents were aged 40-50 years. Most respondents were French (70.3\%), married (73.8\%) and did not report having an active exercise routine (66.0\%). Almost two-thirds of the drivers consumed daily $1-2$ sodas $(34.2 \%)$ or $3-4$ sodas $(33.2 \%)$. Based on the BMI, respondents were divided into normal (34.3\%), overweight $(39.8 \%)$, obese $(19.5 \%)$ or morbidly obese $(9.4 \%)$ categories. The mean BMI was $27.9 \mathrm{~kg} /$ $\mathrm{m}^{2}$ and $51.1 \%$ of LHTDs were current or active smokers. MLR analysis revealed that French LHTDs were more likely (OR=3.04; 95\% CI: $1.62-5.69)$ to have a normal BMI compared to other drivers. Smokers were significantly more likely than non-smokers ( $\mathrm{OR}=2.12 ; 95 \%$ CI: $1.26-3.58)$ to have an above normal BMI. CONCLUSIONS These results confirm that French and other LHTDs are at high risk of non-communicable diseases. They also highlight the need to address the health risks associated with smoking and obesity among LHTDs using multifaceted strategies.
\end{abstract}

\section{AFFILIATION}

1 Raymond Poincaré University Hospital (AP-HP), Versailles SaintQuentin-en-Yvelines University, UMR 1018, France

2 Department of Biobehavioral Health, Penn State University, Pennsylvania, United States 3 Department of Information Mathematics, Penn State University, Pennsylvania, United States

\section{CORRESPONDENCE TO}

Loic Josseran. UFR Simone VeilSanté, 2 Avenue de la Source de la Bièvre, 78280, Montigny-leBretonneux, France.

E-mail: Loic.josseran@aphp.fr ORCID ID: https://orcid.org/00000002-9021-1818

\section{KEYWORDS}

obesity, tobacco, smoking, truck drivers, France, non-communicable diseases

Received: 12 October 2020 Revised: 24 June 2021

Accepted: 15 September 2021

\section{INTRODUCTION}

The number of French workers employed as longhaul transport drivers (LHTDs) exceeds 0.25 million $^{1}$. Despite the vital contribution of road transport to the stability and growth of the French economy and the EU, the health of LHTDs in France has not received sufficient attention.

LHTDs have increased health risks due to the conditions and vagaries of their work schedule, which frequently result in sleep deprivation and disorders, unhealthy or limited dietary intake, and inadequate exercise ${ }^{2,3}$. Studies have also found that LHTDs have higher rates of heart disease, diabetes, and lung cancer, associated with obesity, sedentary lifestyles, tobacco consumption, and the use of stimulants ${ }^{4,5}$. Sieber et al. ${ }^{6}$ found that obese LHTDs had a smoking prevalence rate that was twice that of the general adult population and over two-thirds of respondents were classified as obese. Other studies have found increased risks among LHTDs for psychiatric and psychological disorders, musculoskeletal disease, and sexually transmitted 
disease ${ }^{7-10}$. High demands and low decision latitude, which typify the work experience of professional drivers, have been associated with an increased risk of myocardial infarction ${ }^{5}$. Apostolopoulos et al. ${ }^{7}$ estimated that the life expectancy of male truck drivers was considerably lower than the general population of American men.

Also, studies have shown that obesity may interfere with tasks requiring complex motor skills, concentration and attentive focus such as operating trucks, buses, aircraft, and other transport vehicles. A study conducted in Brazil of 4878 truckers found that increased BMI was significantly associated with shorter sleep duration $(<8 \text { hours })^{11}$. Also, the U.S. Large Truck Crash Causation Study in a rigorous examination of 963 accidents involving a truck found that $13 \%$ were due to exhaustion ${ }^{12}$.

Research by Anderson et al. ${ }^{13}$ found that the crash risk for drivers who were defined as obese was significantly higher than those who had normal BMI scores. Further, obesity is a major public health risk that has been strongly linked to increased cardiovascular disease, diabetes mellitus, hypertension and some cancers, as well as other chronic diseases in France and among truck drivers in other countries ${ }^{5,14}$. A study in 2018 by CarreasTorres et al. ${ }^{15}$ found a complex association between obesity and smoking, suggesting that smoking can reduce obesity as an appetite suppressant but at higher levels of obesity can also increase smoking risks and smoking intensity ${ }^{15}$.

Laws governing intracontinental freight transportation within Europe are regulated by individual countries and the EU. France has one of the highest $\mathrm{km} /$ driver ratios due in part to the shortage of drivers, which is expected to increase by $20 \%$ over a 10 -year period as the profession has less appeal to younger individuals. The shortage of drivers and high turnover rates may indirectly affect the health of workers because of increased pressures to meet delivery timetables and less time for leisure activity $^{16,17}$.

The aim of this article is to describe the smoking and obesity behaviors of truck drivers in France, both French and other. These findings may be useful in understanding differences and patterns in the use of tobacco products, risks factors for obesity, and the combined health risks for tobacco and obesity, among this group of transport workers.

\section{METHODS}

A cross-sectional study was conducted during the Truck Driver Safety Days organized by the nonprofit organization 'Fondation VINCI Autoroutes pour une Conduite responsable' on three multiple days during the months of April and October 2012. The duration of the structured anonymous interview was approximately 30 minutes. The survey interviews were conducted using the IPAD 2 (Apple Inc.). The interviews were conducted by trained investigators at six highway rest areas specially designed for professional truck drivers and equipped with shops, restaurants, and lounges [Aire de Roussillon (A7), Aire de Montélimar (A7), Aire de La Scoperta (A8), Aire de Val Neuvy (A10), Aire de Limours (A10), Aire du Pôle 45 - Saran (A10/A71)] (Figure 1). LHTDs were randomly selected and only the driver at the wheel when the truck entered the rest area (between 4 p.m. and 11 p.m.) was interviewed. Each driver selected had the option not to participate in the study. Intercept methods of truck drivers have been employed in a number of other studies to obtain health data from this difficult-to-reach population ${ }^{18-22}$. A total of 533 drivers were approached and 373 consented, resulting in a sample participation rate of $70 \%$.

\section{Measures}

The questionnaire underwent a number of revisions and was pretested with potential respondents. Variables included self-reported sociodemographic characteristics (age, gender, marital status, and nationality), behavioral variables (consumption of sodas, daily exercise, smoking status). The mean age was 43.4 years and the age variable was categorized as: $<40,40-50,>50$ years. Nationality referred to French or other EU drivers working in France. Active sports engagement was categorized as active or nonactive. The daily use of caffeinated drinks, energy drinks, and sodas was grouped as: $0,1-2,3-4$, and $\geq 5$ sodas. LHTDs were also asked about the weight of their trucks ( $\leq 40$ tons or $>40$ tons), and driving history including any accidents last year (no/yes) and distanced in thousands of $\mathrm{km}$ traveled in the last year $(<125,125-150,>150)$.

Body mass index (BMI) was calculated. BMI (kg/ $\mathrm{m}^{2}$ ) categories were divided into: underweight 
Figure 1. French highways, location of the 6 rest areas (Aire de repos) studied and main French cities

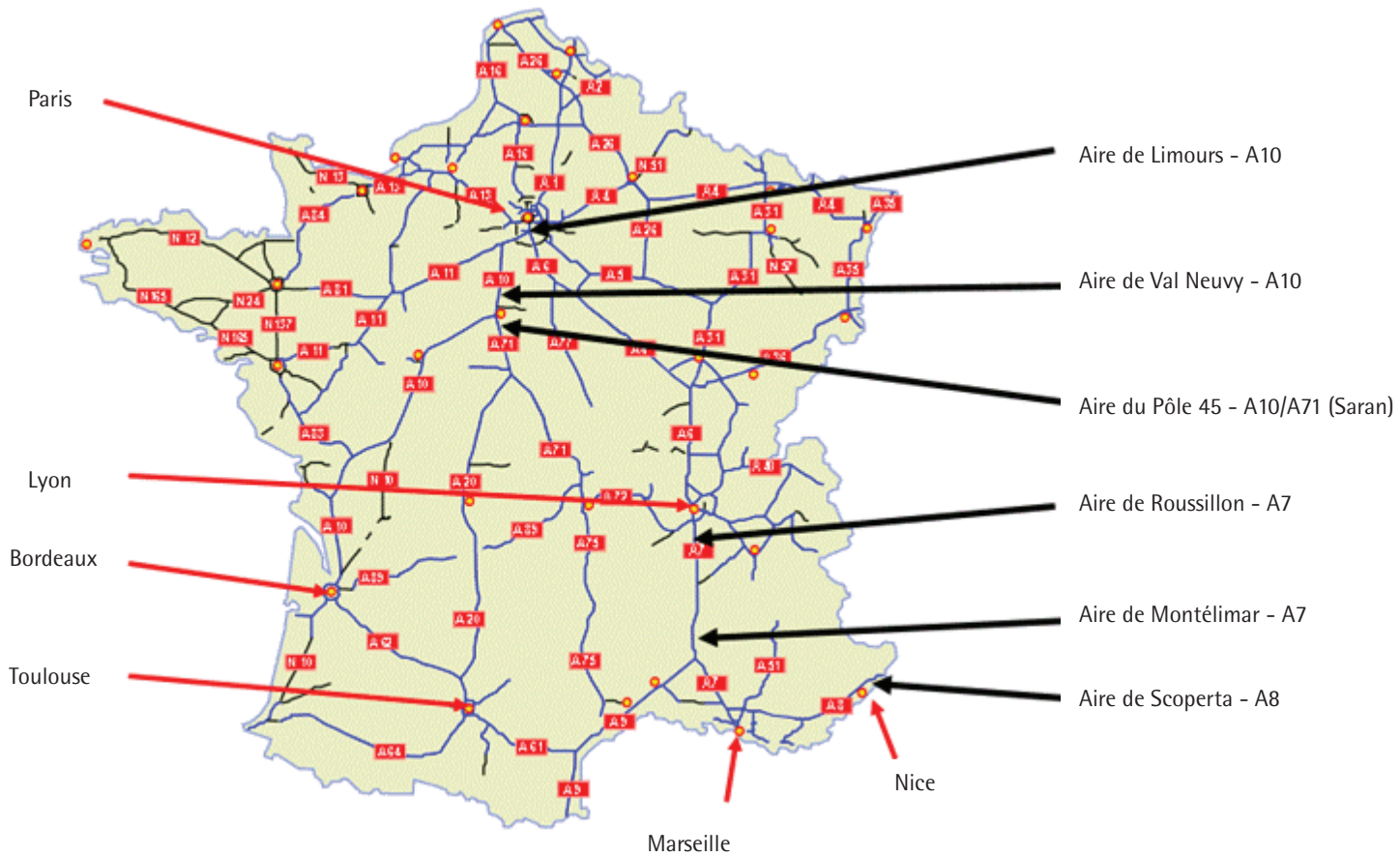

$<18.5$, normal $\geq 18.5$ to $<25.0$, overweight $\geq 25.0$ to $<30.0$, obese $\geq 30$ to $<35$, and morbidly obese $\geq 35$. Smoking status was defined as current consumption of tobacco products and respondents were divided into non-smokers and smokers.

\section{Statistical analysis}

Continuous variables are presented as frequencies, percentages, and means. The BMI mean and standard deviation were calculated for each behavioral variable and age group. Statistical analysis assessing bivariate associations were conducted using chi-square analysis. Multiple logistic ordinal regression (MLR) models were developed to examine the simultaneous effects of predictor variables on each of the two dependent variables: smoking and BMI, separately and combined. SPSS was used to conduct the analysis.

\section{RESULTS}

The mean age of the LHTDs was $43.4 \pm 9.7$ years, and most $(41.2 \%)$ were aged $40-50$ years, French $(70.3 \%)$, married $(73.8 \%)$ and did not report having an active exercise routine $(66.0 \%)$. Almost an equal proportion of drivers consumed daily 1-2 (34.2\%) or $3-4$ sodas $(33.2 \%)$ (Table 1$)$.

The majority (50.8\%) of the LHTDs drove $<125$ thousand $\mathrm{km}$ annually and more than a quarter (28.3\%) drove $125-150$ thousand $\mathrm{km}$. A notable proportion (16.6\%) of truck drivers exceeded 150 thousand $\mathrm{km}$ per year. Most participants drove trucks weighing $>40$ tons and $<10 \%$ indicated that they were involved in an accident in the last year.

Based on the BMI categories, respondents were normal (34.3\%), overweight (39.8\%), obese $(19.5 \%)$, and morbidly obese $(9.4 \%)$. The mean BMI was 27.9 $\pm 4.7 \mathrm{~kg} / \mathrm{m}^{2}$. The results revealed that about half of the participants $(51.1 \%)$ were current or active tobacco users.

Age was significantly related to BMI as older drivers were less likely to have registered a normal BMI $(\mathrm{p}<0.01)$. Almost twice as many French respondents compared to their foreign counterparts $(36.5 \%$ vs $18.9 \%)$ registered a normal BMI $(\mathrm{p}<0.01)$.

Drivers aged $<40$ years $(62.6 \%, \mathrm{p}<0.001)$ were more likely to be smokers than either those aged 4050 years $(53.2 \%)$ and those aged $>50$ years $(33 \%)$, as were French drivers $(54.4 \%, \mathrm{p}<0.05)$ compared to foreign drivers $(43.2 \%)$. Also, married truckers $(60.2 \%, \mathrm{p}<0.05)$ were more likely to be smokers than non-married (47.8\%).

Daily consumption of sodas was significantly $(p<0.05)$ related to BMI, however a clear pattern was 
not apparent.

More than two-thirds of LHTDs with a normal BMI were significantly more likely to be smokers
$(67.5 \%, \mathrm{p}<0.001)$ than those classified as overweight $(44.3 \%)$, obese $(43.8 \%)$, or morbidly obese $(40.0 \%)$. A greater proportion of non-smokers were classified

Table 1. Sociodemographic and transport variables by Body Mass Index (BMI) and smoking status (\%)

\begin{tabular}{|c|c|c|c|c|c|c|}
\hline Variables & $n(\%)$ & Normal & Overweight & Obese & $\begin{array}{c}\text { Morbidly } \\
\text { obese }\end{array}$ & Smokers \\
\hline \multicolumn{7}{|l|}{ Age (years) } \\
\hline$<40$ & $123(32.9)$ & 41.5 & 36.6 & 17.1 & $4.9^{* *}$ & $62.6^{* * *}$ \\
\hline $40-50$ & $154(41.2)$ & 31.8 & 42.2 & 17.5 & 8.4 & 53.2 \\
\hline$>50$ & 97 (25.9) & 31.3 & 39.8 & 19.5 & 9.4 & 33.0 \\
\hline Mean \pm SD & $43.4 \pm 9.7$ & & & & & \\
\hline \multicolumn{7}{|l|}{ Nationality } \\
\hline Other & $111(29.7)$ & 18.9 & 41.4 & 25.2 & $14.4^{*}$ & $43.2^{*}$ \\
\hline French & $263(70.3)$ & 36.5 & 39.2 & 17.1 & 7.2 & 54.4 \\
\hline \multicolumn{7}{|l|}{ Marital status } \\
\hline Single/unmarried & $98(26.2)$ & 35.7 & 38.8 & 16.3 & 9.2 & $60.2^{*}$ \\
\hline Married & $276(73.8)$ & 29.7 & 40.2 & 20.7 & 9.4 & 47.8 \\
\hline \multicolumn{7}{|l|}{ Active sport engagement } \\
\hline Yes & $127(34.0)$ & 37 & 40.9 & 15 & 7.1 & 48.8 \\
\hline No & $247(66.0)$ & 28.3 & 39.3 & 21.9 & 10.5 & 52.2 \\
\hline \multicolumn{7}{|l|}{ Number of sodas daily } \\
\hline 0 & $29(7.8)$ & 34.5 & 41.4 & 10.3 & $13.8^{*}$ & $27.6^{* * *}$ \\
\hline $1-2$ & $128(34.2)$ & 33.6 & 39.1 & 17.2 & 10.2 & 46.1 \\
\hline $3-4$ & $124(33.2)$ & 26.6 & 40.3 & 24.2 & 8.9 & 50.0 \\
\hline$\geq 5$ & $88(23.5)$ & 33 & 40.9 & 19.3 & 6.8 & 68.2 \\
\hline \multicolumn{7}{|c|}{ Distance traveled last year $\left(10^{3} \mathrm{~km}\right)^{*}$} \\
\hline$<125$ & $183(50.8)$ & 32.8 & 40.4 & 22.4 & $4.4^{*}$ & 50.3 \\
\hline $125-150$ & $113(28.3)$ & 29.2 & 38.9 & 17.7 & 14.2 & 54.0 \\
\hline$>150$ & $62(16.6)$ & 30.6 & 41.9 & 11.3 & 16.1 & 50.0 \\
\hline \multicolumn{7}{|l|}{ Truck weight (tons) } \\
\hline$<40$ & $37(9.9)$ & 40.5 & 43.2 & 10.8 & 5.4 & 64.9 \\
\hline$>40$ & $337(90.1)$ & 30.3 & 39.5 & 20.5 & 9.8 & 49.6 \\
\hline \multicolumn{7}{|l|}{ Accidents last year } \\
\hline No & $347(92.8)$ & 31.4 & 39.5 & 19.9 & 9.2 & 51.9 \\
\hline Yes & $27(7.2)$ & 29.6 & 44.4 & 14.8 & 11.1 & 40.7 \\
\hline \multicolumn{7}{|l|}{ BMI $\left(\mathrm{kg} / \mathrm{m}^{2}\right)$} \\
\hline Normal & $117(31.3)$ & & & & & $67.5^{* * *}$ \\
\hline Overweight & $149(39.8)$ & & & & & 44.3 \\
\hline Obese & $73(19.5)$ & & & & & 43.8 \\
\hline Morbidly obese & $35(9.4)$ & & & & & 40.0 \\
\hline Mean \pm SD & $27.9 \pm 4.7$ & & & & & \\
\hline \multicolumn{7}{|l|}{ Smoking status } \\
\hline Non-smoker & $183(48.9)$ & 20.8 & 45.4 & 22.4 & $11.5^{* * *}$ & \\
\hline Current smoker & $191(51.1)$ & 41.4 & 34.6 & 16.8 & 7.3 & \\
\hline \multicolumn{7}{|l|}{ Normal BMI/non-smoker } \\
\hline Non-normal BMI and/or smoker & $336(89.8)$ & & & & & \\
\hline Normal BMI and non-smoker & $38(10.2)$ & & & & & \\
\hline
\end{tabular}

${ }^{*} \chi^{2}$ statistic, $p \leq 0.05 ;{ }^{* *} p<0.01 ;{ }^{* * *} p<0.001$. 
as overweight (45.4\%), obese (22.4\%), and morbidly obese $(11.5 \%)$, compared to current smokers $(\mathrm{p}<0.001)$.

As shown in Table 2, MLR analysis revealed that the probability of having a normal BMI was significantly associated with age, nationality, and smoking status. Respondents who were aged $>50$ years were more likely ( $\mathrm{OR}=2.62$; 95\% CI: $1.24-$
5.54) to have a normal BMI than those aged $<40$ years. Also, French LHTDs were considerably more likely $(\mathrm{OR}=3.04 ; 95 \% \mathrm{CI}: 1.62-5.69)$ to report a normal BMI compared to drivers from other European countries. Smokers were significantly more likely than non-smokers $(\mathrm{OR}=2.12 ; 95 \% \mathrm{CI}$ : 0.1.26-3.58) to have an above normal BMI.

LHTDs who were aged $>50$ years were

Table 2. Logistic regression models for BMI, smoking, BMI and smoking combined

\begin{tabular}{|c|c|c|c|}
\hline & $\begin{array}{l}\text { Normal BMI } \\
\text { OR }(95 \% \text { CI })\end{array}$ & $\begin{array}{c}\text { Smokers } \\
\text { OR }(95 \% \text { CI })\end{array}$ & $\begin{array}{c}\text { Normal BMI/non-smokers } \\
\text { OR (95\% CI) }\end{array}$ \\
\hline \multicolumn{4}{|l|}{ Age (years) } \\
\hline$<40$ & 1 & 1 & 1 \\
\hline $40-50$ & $1.09(0.62-1.92)$ & $0.65(0.37-1.14)$ & $1.14(0.49-2.66)$ \\
\hline$>50$ & $2.62(1.24-5.54)^{*}$ & $0.24(0.12-0.46)^{* * *}$ & $0.72(0.25-2.05)$ \\
\hline \multicolumn{4}{|l|}{ Nationality } \\
\hline Other & 1 & 1 & 1 \\
\hline French & $3.04(1.62-5.69)^{* * *}$ & $1.33(0.78-2.28)$ & $1.44(0.62-3.36)$ \\
\hline \multicolumn{4}{|l|}{ Marital status } \\
\hline Single/unmarried & 1 & 1 & 1 \\
\hline Married & $0.99(0.56-1.75)$ & $0.64(0.37-1.10)$ & $1.28(0.55-3.00)$ \\
\hline \multicolumn{4}{|c|}{ Active sports engagement } \\
\hline No & 1 & 1 & 1 \\
\hline Yes & $1.58(0.95-2.65)$ & $1.45(0.87-2.40)$ & $0.53(0.26-1.11)$ \\
\hline \multicolumn{4}{|c|}{ Number of sodas daily } \\
\hline 0 & 1 & 1 & 1 \\
\hline $1-2$ & $1.46(0.56-3.80)$ & $2.49(0.95-6.48)$ & $0.30(0.10-0.89)^{*}$ \\
\hline $3-4$ & $2.27(0.85-6.09)$ & $3.88(1.46-10.32)^{* *}$ & $0.27(0.09-0.80)^{*}$ \\
\hline$\geq 5$ & $1.93(0.70-5.31)$ & $7.40(2.66-20.59)^{* * *}$ & $0.11(0.03-0.44)^{* *}$ \\
\hline \multicolumn{4}{|l|}{ Truck weight (tons) } \\
\hline$<40$ & 1 & 1 & 1 \\
\hline$>40$ & $1.81(0.75-4.36)$ & $0.34(0.14-0.83)^{*}$ & $1.45(0.31-6.82)$ \\
\hline \multicolumn{4}{|c|}{ Distance traveled last year $\left(10^{3} \mathrm{~km}\right)$} \\
\hline$<125$ & 1 & 1 & 1 \\
\hline $125-150$ & $1.01(0.57-1.78)$ & $1.34(0.78-2.31)$ & $1.71(0.76-3.86)$ \\
\hline$>150$ & $1.03(0.53-2.02)$ & $1.08(0.56-2.08)$ & $0.98(0.35-2.71)$ \\
\hline \multicolumn{4}{|l|}{ Accidents last year } \\
\hline No & 1 & 1 & 1 \\
\hline Yes & $1.39(0.52-3.71)$ & $0.45(0.18-1.14)$ & $1.23(0.34-4.48)$ \\
\hline \multicolumn{4}{|l|}{ Smoking } \\
\hline No & 1 & & \\
\hline Yes & $2.12(1.26-3.58)^{* *}$ & & \\
\hline \multicolumn{4}{|l|}{ BMI } \\
\hline Normal & & 1 & \\
\hline Overweight & & $0.44(0.25-0.78)^{* *}$ & \\
\hline Obese & & $0.48(0.24-0.97)^{*}$ & \\
\hline Morbidly obese & & $0.58(0.24-1.40)$ & \\
\hline
\end{tabular}

${ }^{*} p \leq 0.05 ;{ }^{* *} p<0.01 ; * * * p<0.001$. 
significantly less likely to be smokers compared to those aged $<40$ years $(\mathrm{OR}=0.24 ; 95 \%$ CI: $0.12-$ $0.46)$. LHTDs who daily consumed either 3-4 sodas $(\mathrm{OR}=3.88 ; 95 \% \mathrm{CI}: 1.46-10.32)$ or $>5$ sodas $(\mathrm{OR}=7.40 ; 95 \%$ CI: 2.66-20.59) were highly more likely to be smokers than those who reported typically drinking no beverages during the day. Drivers who were overweight or obese were less likely $(\mathrm{OR}=0.44 ; 95 \% \mathrm{CI}$ : $0.25-0.78$ and $\mathrm{OR}=0.48$; 95\% CI: 0.24-0.97, respectively) to be current smokers than those who had normal BMI values.

In the model predicting a reduced health risk, combining both BMI and smoking status, the number of beverages consumed per day was strongly and significantly associated with a normal BMI and non-smoker status. Respondents who daily consumed either $1-2(\mathrm{OR}=0.30$; 95\% CI: $0.10-0.89)$, $2-3(\mathrm{OR}=0.27 ; 95 \%$ CI: $0.09-0.80)$, or $>5$ sodas $(\mathrm{OR}=0.11 ; 95 \%$ CI: 0.03-0.44) were significantly less likely to have a normal BMI and to have abstained from tobacco consumption.

\section{DISCUSSION}

As the first study to examine smoking and obesity among LHTDs in France, this work adds considerably to our understanding of the health hazards and potential dangers facing transport workers. These workers are subject to occupational risks including social costs affecting their personal lives and families, and consequentially society at large. These findings may serve as baseline indices to assess progress in improving the health of LHTDs in France, particularly with respect to smoking prevalence and obesity.

In France, the epidemiology of smoking differs from that of the United States where the consumption of tobacco has diminished considerably among all demographic groups and is less than half the prevalence of the French population ${ }^{23}$. However, the proportion of smokers in the US among LHTDs (51\%) reported in a large study by Sieber et al. ${ }^{6}$ was virtually identical $(51.1 \%)$ to the rate of smoking found in the present study ${ }^{6}$. They also found that $68.9 \%$ of US LHTDs were obese and $17.4 \%$ were morbidly obese. The comparable figures for French truckers in our study were much lower, $17.2 \%$ and $7.1 \%$, respectively. Interestingly, young drivers were significantly more likely to be smokers than their older counterparts and this finding was unrelated to nationality. This result has implications for the future health of truckers as the potential occupational longevity of younger drivers may portend cumulative risks for tobacco related illnesses.

Our analysis revealed a statistically significant association between smoking status and beverage consumption. Other studies have shown a positive relationship between caffeine consumption and nicotine consumption, and caffeine use has been shown to increase the likelihood of nicotine dependence using animal models ${ }^{24-27}$. Coffee and other caffeinated drinks may contain high proportions of sugar and other ingredients that are not conducive to healthy diets and could exacerbate existing health problems ${ }^{24}$.

Tobacco use has been shown to be correlated with daytime sleepiness in truck drivers and caffeine use has been shown to reduce fatigue and related accidents in truck drivers, which suggests that the use of nicotine and caffeine conjunctively may produce antagonistic effects on sleepiness and sleeprelated accidents ${ }^{28,29}$.

It has been shown that novelty seeking is a predictor of both caffeine and nicotine use and that cocaine users drink more caffeinated beverages per day than the general population, although they are less likely overall to consume caffeinated beverages ${ }^{30,31}$. Speculatively, it is possible that caffeinated beverage consumption acts as a predictor of addictive behaviors and that those who consume a variety of caffeinated beverages are also more likely to engage in the use of stimulants, irrespective of outside factors. Although beyond the scope of this study, future studies may benefit from the exploration of caffeinated beverage consumption in relation to illicit drug use among transport workers.

BMI was found to be related to the nationality and smoking status, which may have moderated obesity in this sample of LHTDs, as smoking cigarettes is an appetite suppressant ${ }^{32}$. It is not surprising that the BMI of French truck drivers was much lower than those of other nationality LHTDs. Also, somewhat speculatively, the cultural influence of dietary habits and nutrition on other nationality LHTDs could account for differences in obesity prior to their employment as French truckers. Moreover, the combined health effects of cigarette consumption 
and obesity increase the likelihood of negative health consequences.

Public policy monitoring and controlling the work schedules, conditions, and health requirements of LHTDs in France are determined both by national and EU deliberations and dictates. Although the EU has several umbrella regulations governing its member states with respect to driving hours (e.g. daily driving period shall not exceed 9 hours) and rest periods (e.g. daily rest period shall be at least 11 hours), there are no standard health guidelines, minimal criteria, or systemic means of monitoring the health of its drivers ${ }^{33}$. Restrictions on LHTDs in France are more stringent than in the EU (e.g. highly restrictive driving on Sunday or holidays, restricted speed limits, mandatory stops every 4.5 hours for at least 45 minutes). Also, in France, medical exams are required to obtain a long-haul truck driving license, and periodic exams are required every 5 years, at 60 years every two years, and at $60-76$ years every year, and every year thereafter for those aged $>76$ years $^{34}$.

More importantly, at present, there is a paucity of preventive health programs addressing the needs and problems of LHTDs in France. A comprehensive wellness programs, voluntary or otherwise, consisting of health education modules, exercise, and literature aimed at reducing obesity and tobacco consumption, and other health topics at rest stops or in companies, could potentially save lives and benefit employees, employers, and the society at large $\mathrm{e}^{35,36}$. For example, in their systematic review of prevention programs for truck drivers, $\mathrm{Ng}$ et al.$^{35}$ found that interventions resulting in statistically significant BMI improvements not only focused on individuals but also included modules such as group education/ counseling and theory-based strategies (e.g. stages of change theory). Their analysis also revealed that two smoking cessation programs yielded significant reductions in tobacco use among $\mathrm{LHTDs}^{36}$.

\section{Limitations}

This study is limited by the small sample size of 374 participants, of whom about $30 \%$ were nonnative French transport workers. Future studies of this population should include a larger number of participants and more varied methods of data collection. Additionally, self-reported information about personal health behavior is always subject to some form of bias. The use of objective indices (e.g. biochemical validation, weight/height scales) could reduce bias. Also intercept studies, while quite useful in reaching difficult to study groups such as LHTDs, are intrinsically problematic as noted by Sieber et al. ${ }^{6}$ because they miss drivers who are unavailable due to vacations, work schedules, illness or other reasons for not working. Some study variables including tobacco consumption, use of caffeinated drinks and alcohol, sleeping habits, exercise, and other behaviors and risks were not measured in sufficient detail to adequately determine frequency and other attributes.

\section{CONCLUSIONS}

LHTDs provide an essential societal function in transporting a nation's goods and products daily under occupational conditions that can be vastly improved, particularly with respect to health and medical consequences. Maintaining a healthy and alert workforce of LHTDs can also improve the highway safety of the general population by reducing vehicle accidents involving LHTDs, which have higher fatality rates. This study points to the need to address health risks associated with smoking and obesity of LHTDs in France. In this regard, a multifaceted set of strategies should be considered entailing empirical studies focusing on specific health risks and medical problems; designing, implementing, and evaluating interventions in collaboration with drivers, unions, and employers; improving the challenging working and structural conditions of long-haul trucking under which drivers worked; and legislative initiatives that protect and enhance the health of LHTDs.

\section{REFERENCES}

1. Eurostat. Key figures on Europe. European Union; 2017. Accessed May 1, 2021. http://ec.europa.eu/eurostat/ documents/3217494/7827738/KS-EI-16-001-EN-N. pdf/bbb5af7e-2b21-45d6-8358-9e130c8668ab

2. Mitler MM, Miller JC, Lipsitz JJ, Walsh JK, Wylie CD. The sleep of long-haul truck drivers. N Engl J Med. 1997;337(11):755761. doi:10.1056/NEJM199709113371106

3. Birdsey J, Sieber WK, Chen GX, et al. National Survey of US Long-Haul Truck Driver Health and Injury: health behaviors. J Occup Environ Med. 2015;57(2):210-216. doi:10.1097/JOM.0000000000000338

4. Robinson CF, Burnett CA. Truck drivers and heart disease in the United States, 1979-1990. Am J Ind Med. 2005;47(2):113-119. doi:10.1002/ajim.20126

5. Bigert C, Gustavsson P, Hallqvist J, et al. Myocardial infarction 
among professional drivers. Epidemiology. 2003;14(3):333339. doi:10.1097/01.EDE.0000057141.91012.80

6. Sieber WK, Robinson CF, Birdsey J, et al. Obesity and other risk factors: the national survey of U.S. longhaul truck driver health and injury. Am J Ind Med. 2014;57(6):615-626. doi:10.1002/ajim.22293

7. Apostolopoulos Y, Sönmez S, Shattell MM, Belzer M. Worksite-induced morbidities among truck drivers in the United States. AAOHN J. 2010;58(7):285-296. doi:10.3928/08910162-20100625-01

8. Magnusson ML, Pope MH, Wilder DG, Areskoug B. Are occupational drivers at an increased risk for developing musculoskeletal disorders? Spine. 1996;21(6):710-717. doi:10.1097/00007632-199603150-00010

9. Miyamoto M, Shirai Y, Nakayama Y, Gembun Y, Kaneda K. An epidemiologic study of occupational low back pain in truck drivers. J Nippon Med Sch. 2000;67:186-190. doi:10.1272/jnms.67.186

10. Stratford D, Ellerbrock TV, Akins JK, Hall HL. Highway cowboys, old hands, and Christian truckers: risk behavior for human immunodeficiency virus infection among longhaul truckers in Florida. Soc Sci Med. 2000;50(5):737749. doi:10.1016/S0277-9536(99)00335-4

11. Moreno CR, Louzada FM, Teixeira LR, Borges F, LorenziFilho G. Short sleep is associated with obesity among truck drivers. Chronobiol Int. 2006;23:1295-1303. doi:10.1080/07420520601089521

12. Starnes M. Large-Truck Crash Causation Study: An Initial Overview. U. S. Department of Transportation, NHTSA; 2006. DOT HS 810 646. Accessed May 1, 2021. https://crashstats.nhtsa.dot.gov/Api/Public/ ViewPublication/810646

13. Anderson JE, Govada M, Steffen TK, et al. Health behavior and accident risk: Obesity is associated with the future risk of heavy truck crashes among newly recruited commercial drivers. IZA; 2012. Discussion Paper No. 6408. Accessed May 1, 2021. http://nbn-resolving.de/ urn:nbn:de:101:1-201206146961

14. Cavagioni LC, Geraldo Pierin AM. Hypertension and obesity among professional drivers who work transporting loads. Acta Paul Enferm. 2010;23(4):455460. doi:10.1590/S0103-21002010000400002

15. Carreras-Torres R, Johansson M, Haycock PC, et al. Role of obesity in smoking behaviour: Mendelian randomisation study in UK Biobank. BMJ. 2018;361:k1767. doi:10.1136/bmj.k1767

16. Eurostat. Europe in figures: Eurostat 2102. European Union; 2013. Accessed May 1, 2021. http://ec.europa. eu/eurostat/documents/3217494/5760825/KS-CD-12001-EN.PDF

17. McCartt AT, Rohrbaugh JW, Hammer MC, Fuller SZ. Factors associated with falling asleep at the wheel among longdistance truck drivers. Accid Anal Prev. 2000;32(4):493504. doi:10.1016/S0001-4575(99)00067-6

18. Solomon AJ, Doucette JT, Garland E, McGinn T.
Healthcare and the long haul: long distance truck drivers - a medically underserved population. Am J Ind Med. 2004;46(5):463-471. doi:10.1002/ajim.20072

19. Belman DL, Monaco AK, Brooks TJ. Sailors on the concrete sea: A portrait of truck drivers' work and lives. Michigan State University Press; 2005.

20. Williamson A, Cooley M, Hayes L, O’Neill L. Final report of stimulant use by long distance road transport drivers project. New South Wales Injury Risk Management Research Centre; 2006:103.

21. Bigelow PI, Betts D, Hogg-Johnson S, et al. Health, safety, and wellness of truck drivers in Canada: Results of a pilot study. In: Research on the health and wellness of commercial truck and bus drivers. The National Academies Press; 2012:144.

22. Angeles R, McDonough B, Howard M, et al. Primary health care needs for a priority population: a survey of professional truck drivers. Work. 2014;49(2):175-181. doi:10.3233/WOR-131649

23. King G, Guignard R, Reeder E, et al. Fumestu encore? Quitting among French and American smokers: 2000-2010. Ann Epidemiol. 2019;34:26-32. doi:10.1016/j.annepidem.2019.03.012

24. Malik VS, Schulze MB, Hu FB. Intake of sugar-sweetened beverages and weight gain: a systematic review. Am J Clin Nutr. 2006;84(2):274-288. doi:10.1093/ajcn/84.2.274

25. Swanson JA, Lee JW, Hopp JW. Caffeine and nicotine: A review of their joint use and possible interactive effects in tobacco withdrawal. Addict Behav. 1994;19(3):229-256. doi:10.1016/0306-4603(94)90027-2

26. Istvan J, Matarazzo JZ. Tobacco, alcohol, and caffeine use: A review of their interrelationships. Psychol Bull. 1984;95(2):301-326. doi:10.1037/0033-2909.95.2.301

27. Gasior M, Jaszyna M, Munzar P, Witkin JM, Goldberg SR. Caffeine potentiates the discriminative-stimulus effects of nicotine in rats. Psychopharmacology. 2002;162(4):385395. doi:10.1007/s00213-002-1113-3

28. Braeckman L, Verpraet R, Van Risseghem M, Pevernagie D, De Bacquer D. Prevalence and Correlates of Poor Sleep Quality and Daytime Sleepiness in Belgian Truck Drivers. Chronobiol Int. 2011;28(2):126-134. doi:10.3109/07420528.2010.540363

29. Sharwood LN, Elkington J, Meuleners L, Ivers R, Boufous S, Stevenson M. Use of caffeinated substances and risk of crashes in long distance drivers of commercial vehicles: case-control study. BMJ. 2013;346:f1140. doi:10.1136/bmj.f1140

30. Gurpegui M, Jurado D, Luna JD, Fernández-Molina C, Moreno-Abril O, Gálvez R. Personality traits associated with caffeine intake and smoking. Prog Neuropsychopharmacol Biol Psychiatry. 2007;31(5):9971005. doi:10.1016/j.pnpbp.2007.02.006

31. Budney AJ, Higgens ST, Hughes JR, Bickel WK. Nicotine and caffeine use in cocaine-dependent individuals. J Subst Use. 1993;5(2):117-130. doi:10.1016/0899-3289(93)90056-H 
32. Chen H, Vlahos R, Bozinovski S, Jones J, Anderson GP, Morris MJ. Effect of short-term cigarette smoke exposure on body weight, appetite and brain neuropeptide $\mathrm{Y}$ in mice. Neuropsychopharmacology. 2005;30(4):713-719. doi:10.1038/sj.npp.1300597

33. European Union. Regulation (Ec) No 561/2006 of the European Parliament and of the Council of 15 March 2006 on the harmonisation of certain social legislation relating to road transport and amending Council Regulations (EEC) No 3821/85 and (EC) No 2135/98 and repealing Council Regulation (EEC) No 3820/85. Accessed May 1, 2021. https://eur-lex.europa.eu/ resource.html?uri=cellar:5cf5ebde-d494-40eb-86a72131294ccbd9.0005.02/DOC_1\&format=PDF

34. Order of 2 March 2015 on the ban on the movement of goods transport vehicles during certain periods. Official Collective Agreement Bulletins. French Republic; 2015. NOR: DEVT1500238A. Accessed May 1, 2021. https://www.legifrance.gouv.fr/jorf/id/ JORFTEXT000030337222

35. Ng MK, Yousuf B, Bigelow PL, Van Eerd D. Effectiveness of health promotion programs for truck drivers: A systematic review. Health Educ J. 2015;74(3):270-286. doi:10.1177/0017896914533953

36. Sorensen G, Stoddard A, Quintiliani L, et al. Tobacco use cessation and weight management among motor freight workers: Results of the Gear Up for Health Study. Cancer Causes Control. 2010;21(12):2113-2122. doi:10.1007/s10552-010-9630-6
ACKNOWLEDGEMENTS

The authors thank B. Moreau of the Fondation Vinci Autoroutes pour une conduite responsable for her help in the implementation of this project.

\section{CONFLICTS OF INTEREST}

The authors have each completed and submitted an ICMJE Form for Disclosure of Potential Conflicts of Interest. The authors declare that they have no competing interests, financial or otherwise, related to the current work. All authors report funding from Fondation Vinci Autoroutes pour une conduite responsable. M. A. Quera Salva also reports grands from Vanda and honoraria from Biocedex, outside the submitted work.

\section{FUNDING}

This work was supported by the Fondation Vinci Autoroutes pour une conduite responsable.

\section{ETHICAL APPROVAL AND INFORMED CONSENT}

This study was registered by the institutional review board of the Commission Nationale Informatique et Liberté (No. 2220953, v0) in France and approved by the Saint Germain-en-Laye research ethics committee. Informed consent was not required as existing data were used.

\section{DATA AVAILABILITY}

Data sharing is not applicable to this article as no new data were created.

\section{AUTHORS' CONTRIBUTIONS}

Research concept and design: $\mathrm{D}, \mathrm{TF}, \mathrm{RS}, \mathrm{FB}$ and M-AOS. Collection and/ or assembly of data: $\mathrm{L}, \mathrm{TF}, \mathrm{RS}$ and FB. Data analysis and interpretation: $\mathrm{U}$, KMN, MB and GK. Writing the manuscript: $\sqcup$ and GK. Critical revision of the manuscript: $\sqcup, K M N, R S, F B, M-A O S, M B$ and GK. Final approval of the manuscript: $\sqcup, \mathrm{KMN}$ and GK.

PROVENANCE AND PEER REVIEW

Not commissioned; externally peer reviewed. 